\title{
The reliability of estimates of migration in the peppered moth Biston betularia and some implications for selection-migration models
}

\author{
PAUL M. BRAKEFIELD
}

Section of Evolutionary Biology, Department of Population Biology, Schelpenkade 14a, 2313 ZT Leiden, The Netherlands

AND

TONY G. LIEBERT

The Heathfield, Crowcombe Heathfield, Lydeard St Lawrence, Taunton

\begin{abstract}
Migration of adult males is one of the important variables involved in the mathematical models of industrial melanism in Biston betularia. Values for this variable are based on data from a capturerecapture performed by Bishop (1972) using both local and bred moths which were at least one night old at release. We carried out an experiment to compare the rate of recapture close to the point of release for moths allowed to fly away immediately after their emergence around dusk and those which were at least one night old at release. Unheld moths were less likely to be recaptured suggesting that males have an initial dispersal phase on their first night which results in a higher rate of emigration than on subsequent nights. Such a phase would have been largely missed in Bishop's experiment. The implications of this type of behaviour pattern for the models of spatial variation based on a selection-migration balance are discussed.
\end{abstract}

KEY WORDS: - Biston betularia - peppered moth - industrial melanism - migration - dispersal behaviour - mathematical models - evolution.

\section{CONTENTS}

Introduction.$\quad 335$

Background: J. A. Bishop's experiment . . . . . . . . . . . . . 336

A new experiment. . . . . . . . . . . . . 337

Methods . . . . . . . . . . . . . . . . 337

Results . . . . . . . . . . 338

Discussion . . . . . . . . . . . . . . 339

Implications for selection-migration models. . . . . . . . . . . . 339

References . . . . . . . . . . . . . . 341

\section{INTRODUCTION}

One important variable used in mathematical models of the evolution of industrial melanism in the peppered moth Biston betularia (see review by Mani, 
1990 ) is the migration rate of adult males. Whittle et al. (1976) and Bishop, Cook \& Muggleton (1978) have argued that migration may be the most important factor maintaining polymorphism in regions of high industrial air pollution. Although the results of the mathematical models developed by Mani (1980, 1982, 1990) and Cook \& Mani (1980) are quite robust with respect to variation in the average distance-moved by moths, it remains necessary to consider how accurate the available estimates of migration are. The only empirical data describing the movement of adult males are from an influential capturerecapture experiment performed by Bishop (1972) as part of his experimental analysis of the cline of declining frequency of the black melanic form carbonaria from urban Liverpool to rural North Wales. The marked males released by Bishop were not freshly emerged and in view of the decline in flight activity of female moths with age (Liebert \& Brakefield, 1987) we carried out an experiment to examine whether a similar phenomenon occurs in males.

\section{BACKGROUND: J. A. BISHOP'S EXPERIMENT}

The mathematical models have assumed that female peppered moths do not move. We have previously made observations on females in cages and when released onto trees following holding in captivity for varying numbers of nights (Liebert \& Brakefield, 1987). These showed that females do disperse on the first night following their eclosion. Most females probably only fly for a short time and, therefore, may not move very far. What is probably more significant is that flight activity is greatly reduced on subsequent nights to the extent that the majority of females are likely to mate and oviposit on the same tree they settle on following their initial dispersal phase.

The multiple-capture-recapture experiment performed by Bishop (1972) used releases both of males collected in the field and of males bred and emerged in captivity. The wild males must have been at least one night old when they were released before dark between 18.00 and 21.00 hours B.S.T. Bishop states that the reared males were "stored in pill boxes which were kept cold" and that the experiment allowed him to compare the ability to assemble of the wild males with those "known to have emerged in the $24 \mathrm{~h}$ previous to their release". Since almost all peppered moths eclose in the evening after 18.00 hours these comments indicate that the cohort of bred moths used by Bishop were one night old at the time of their release. If males disperse more on their first night, or if they are then more likely to emigrate from the area they emerge in, the capturerecapture experiment may have seriously underestimated the rate of migration in the wild.

Bishop's experiment was designed to maintain an approximately uniform density of assembly traps over a circular area of up to $5 \mathrm{~km}$ from a central release point thus minimizing spatial variation in sampling intensity. Bishop showed that male moths did not disperse out of the area of release according to the rate expected from a simple diffusion model in which the proportion of marked moths captured by the traps within an annulus declined as a reciprocal of its distance from the centre. He concluded that the moths did not 'diffuse' out of the area of release in an orderly way and that more complex patterns of movement were involved. The released moths either tended to remain very near the area of release or to fly a considerable distance of more than about $3 \mathrm{~km}$. Twenty-five 
per cent of moths moved more than $2 \mathrm{~km}$. About two-thirds of recaptures had moved very short distances. Clearly any variation in this proportion would greatly influence estimates of migration rate. Furthermore, a substantial 'tail' of moths migrating long distances (say more than $5 \mathrm{~km}$, see Bishop, 1972) could strongly affect spatial patterns of gene frequency, especially if most of these moths move before pairing. The preliminary experiment reported here was designed to determine whether the age of moths influences the proportion exhibiting the sedentary mode of behaviour.

Bishop (1972) also developed a mathematical model of the cline from Liverpool to North Wales which was based on a series of 27 units each representing $2 \mathrm{~km}$ of the cline. In addition to incorporating estimates of selective predation, heterozygous advantage and initial gene frequency, he assumed that one in five male moths moved between adjacent units per generation. The initial model provided a poor fit to the observed cline both in terms of shape and position. The fit was improved somewhat when the apparent leptokurtic pattern of movement was taken into account, although the modelled cline remained displaced from the observed cline. Later and more sophisticated models, both of this cline and other patterns of spatial variation in England and Wales, are based on an interpretation of Bishop's data as indicating that males move an average of $2.5 \mathrm{~km}$ per night (see Mani, 1990). Migration is modelled as a Gaussian function so that leptokurtosis is not taken into account.

\section{A NEW EXPERIMENT}

\section{Methods}

The new experiment was performed in the centre of the small city of Leiden in The Netherlands. Males used in the experiment were either local males collected in assembly traps or moths bred from an English stock. Moths were released daily from 23 June to 19 July 1988. Most of this period corresponded to a time of comparatively high moth density. It fell at the end of the flight season; no moths being caught before 20 May or after 19 July. Three assembly traps were distributed over an area of several hectares centred on the Botanic Gardens. In addition, about ten female moths which were three nights old were released each night during the early part of the experiment (up to 1 July) onto trees spaced out around a 'ring' of some $150 \mathrm{~m}$ in diameter extending into a built-up area to one side of the Botanic Gardens. This method of release was developed by Liebert \& Brakefield (1987) to study female behaviour. Most of these females remain on the tree of their release and any pairings with free-flying males can be recorded and the males marked. Additional assembly traps or released females placed at various sites about $1 \mathrm{~km}$ or $5 \mathrm{~km}$ distant from the study area failed to catch any marked males.

Almost all bred moths emerged between 18.00 and 24.00 hours, dusk falling at about 22.30 hours. The distribution of male emergence over this time when divided into three consecutive periods of about $2 \mathrm{~h}$, approximated the ratio 1:2:1 (Table 1). Moths were date-marked with colour dots from permanent marker pens. Moths successfully emerging in covered tubs between 18.00 and c. 22.00 hours could be marked and placed on perches in bushes, trees or walls from which they could fly off naturally the same evening. The cohorts of 
because of mating) suggesting that such a difference between fresh and older moths is likely to occur in fully natural conditions. A higher recapture rate for moths which are at least one night old was maintained in the second part of the experiment. The third part of the experiment emphasizes that when local moths and bred moths which have been held for two nights are released in the vicinity of assembly traps, about one in five of each cohort are likely to be recaptured. There is no heterogeneity in recapture rate among the three cohorts of local males or of held moths.

\section{DISCUSSION}

Release experiments must always be interpreted with caution. The experiments with $B$. betularia involve releases of an unnaturally high density of moths and however carefully the mark-release procedure is carried out it is likely to cause some effect on behaviour. Aliens may be more likely to emigrate than locals (see Endler, 1977). Nevertheless in the present experiment the lower rate of recapture among moths released immediately after eclosion than among those released when they were at least one night old requires explanation. Although numbers of recaptures are small, there was a roughly tenfold difference in recapture rate in the first period of the experiment (Table 1). The most likely explanation is that males are more likely to emigrate from the vicinity of their site of eclosion or of daytime resting during their first night than on subsequent nights. Most males are probably unlikely to find a receptive female on their first night because of competition with older, local males whose wings and genitalia are fully hardened. Released females which pair usually assemble males and mate shortly after dark before about 23.00 hours (Liebert \& Brakefield, 1987). Inspection of our released 'unheld' moths on their perches showed that some moths had not left by this time. Therefore, by the time freshly eclosed males, especially those emerging in the hour or two before dusk, are likely to be capable of pairing, most receptive females will have mated. Our released moths on taking flight around dusk tended to fly rapidly more or less directly upwards and out of sight. These observations suggest that males exhibit an initial active dispersal or migratory phase and that this is unlikely to result in a reduced pairing success relative to males which do not exhibit this behaviour. It would be interesting to determine whether males are responsive to the female pheromone during their initial flight.

Our observations from this study and the earlier work (Liebert \& Brakefield, 1987) can be summarized by the following scenario. Most females probably mate on their first night soon after a short dispersal flight following dusk. In contrast, many males migrate on their first night and are unlikely to mate because of competition from local, old males for the comparatively small proportion of calling females. Females will tend to pair with males which have survived at least one day in the vicinity of the pairing site although this may be some kilometres away from where they developed and emerged. Further detailed work is necessary to substantiate this scenario and to quantify the phenomena.

\section{Implications for selection-migration models}

Clearly the present experiment and that of Bishop (1972) differ in several features of design. The proportion of recaptures made by Bishop very close to 
release was at $8.4 \%$, intermediate between our rates of recapture for local and unheld moths (21.0 and $1.8 \%$, respectively). There may be a more specific problem in trying to relate our observations to the results of Bishop's experiment. While our held moths were able to fly when in captivity the bred males which were released by Bishop had been held in cooled pill boxes and, therefore, had not flown prior to release. The same is clearly not the case for his wild males which were presumably in a similar state to the local males we released. Furthermore, Bishop's table 9 indicates that bred males comprised the minority of his releases (about 13\%). Therefore, a stronger tendency of freshly eclosed males to emigrate than moths which are older than one night may mean that the estimates of migration rate from Bishop's experiment seriously underestimate this parameter. The effect of any such discrepancy on the average distance-moved is likely to be exaggerated by a leptokurtic distribution of distance-moved as demonstrated by Bishop (1972). Perhaps fortunately the extraction from Bishop's data of a value for the average distance-moved by a male moth per night for input into the later mathematical models (Mani, 1990) appears to have erred on the generous side. Thus his tables 3 and 4 show that this mean value for his releases was $1.15 \mathrm{~km}$ while the models have concentrated on a value of $2.5 \mathrm{~km}$. Even so we consider that attention should be paid to obtaining more reliable estimates of migration and also of taking the probability of long-distance movement of many males in their initial dispersal phase into account. Similarly, long-distance movement, perhaps more directional in nature, may also occur by passive dispersal of newly hatched larvae on the wind or thermals (see Liebert \& Brakefield, 1987).

A general point of concern about the models is that they assume that selection takes place before migration for the runs corresponding to each day of the flight period. If the above scenario is largely true and, in particular, if male (and female) migration tends to occur on the first night, moths emerging around dusk, then predation by birds in nature will tend to occur after, rather than before, migration. The short expectation of adult life would increase the possible bias which may be introduced by applying selection before migration in the models.

We also note with respect to the models of the cline of decreasing frequency of carbonaria melanics from Liverpool to North Wales that one of the seven selective predation experiments using cohorts of dead moths glued to tree trunks was carried out at Hawarden about halfway along the transect and near the point of inflexion in the cline (Bishop, 1972). This locality was close to the large coalfired steel works at Shotton and was associated with local increases in air pollution and melanic frequencies in B. betularia and Gonodontis bidentata (Bishop, 1972; Bishop \& Cook, 1975; Bishop et al., 1978). The frequency of carbonaria at Hawarden was $87 \%$ (Bishop, 1972) and the species diversity of epiphytes on oak trees was low (Bishop et al, 1975). The estimated selection coefficient derived from the predation experiment performed at Hawarden suggested that, if anything, typica non-melanics were favoured over carbonaria. It is unfortunate that the experiment was not replicated to check the reliability of this estimate based on 104 moths since this point has a substantial influence on the form of the fitness curve employed in the models. If visual selection actually favoured carbonaria at Hawarden in 1972 it is unlikely that the fitness curve would approximate to a rectilinear relationship (see fig. 7 in Bishop, 1972). Such a departure could help to account for the difference in position between the 
observed cline and the model clines based on a balance between visual selection and migration; the latter being displaced towards Liverpool. It would also be interesting to exclude the estimates for Hawarden and model the cline running along a more direct transect from the Liverpool sites to those in North Wales (see fig. 1 in Bishop, 1972). The cline along such a transect would have had a point of inflexion substantially closer to the model clines involving only visual selection and migration which have already been developed (see Mani, 1990).

While we recognize that the modelling approach has not been taken in an attempt to provide any more or less complete explanation of industrial melanism in $B$. betularia, our remarks emphasize the need for more detailed information on the population biology of the species and for more experimental work. This will be required before any such explanation can be expected.

\section{REFERENCES}

BISHOP, J. A., 1972. An experimental study of the cline of industrial melanism in Biston betularia (L.) (Lepidoptera) between urban Liverpool and rural North Wales. Journal of Animal Ecology, 41: 209243.

BISHOP, J. A. \& COOK, L. M., 1975. Moths, melanism and clean air. Scientific American, 232: $90-99$.

BISHOP, J. A., COOK, L. M. \& MUGGLETON, J., 1978. The response of two species of moths to industrialization in northwest England. I. Polymorphisms for melanism. Philosophical Transactions of the Royal Society of London, Series B, 181: 489-515.

BISHOP, J. A., COOK, L. M., MUGGLETON, J. \& SEAWARD, M. R. D., 1975. Moths, lichens and air pollution along a transect from Manchester to North Wales. Journal of Applied Ecology, 12: 83-98.

COOK, L. M. \& MANI, G. S., 1980. A migration-selection model for the morph frequency variation in the peppered moth over England and Wales. Biological Journal of the Linnean Society, 13: 179-198.

ENDLER, J. A., 1977. Geographic Variation, Speciation and Clines. New Jersey: Princeton University Press.

LIEBERT, T. G. \& BRAKEFIELD, P. M., 1987. Behavioural studies on the peppered moth Biston betularia and a discussion of the role of pollution and lichens in industrial melanism. Biological Journal of the Linnean Society, 31: 129-150.

MANI, G. S., 1980. A theoretical study of morph ratio clines with special reference to melanism in moths. Proceedings of the Royal Society of London, Series B, 210: 299-316.

MANI, G. S., 1982. A theoretical analysis of the morph frequency variation in the peppered moth over England and Wales. Biological Journal of the Linnean Society, 17: 259-267.

MANI, G. S., 1990. Theoretical models of melanism in Biston betularia - a review. Biological Journal of the Linnean Society, 39: 355-371.

WHITTLE, P. D. J., CLARKE, C. A., SHEPPARD, P. M. \& BISHOP, J. A., 1976. Further studies on the industrial melanic moth Biston betularia (L.) in the north-west of the British Isles. Proceedings of the Royal Society of London, Series B, 194: 467-480. 